\title{
ARTIGOS
}

Submetido 23.06.2015. Aprovado 30.11.2015

Avaliado pelo processo de double blind review. Editora Científica: Patrícia Mendonça

DOI: http://dx.doi.org/10.1590/So034-759020160207

\section{MODELO DE NEGÓCIOS COM IMPACTO SOCIAL}

\author{
Business model with a social impact \\ Modelo de negocios con impacto social
}

\section{RESUMO}

Entre as alternativas pela busca do desenvolvimento sustentável estão os negócios com impacto social, ou seja, aqueles que são desenvolvidos para atender a algum tipo de demanda social e com atuação rentável. 0 objetivo desta pesquisa foi propor um modelo de negócios com impacto social que auxilie na identificação de seus elementos. 0 modelo de negócio proposto diferencia-se dos já existentes por compilar vários deles e, principalmente, por detalhar os elementos que o constituem. 0 método de pesquisa baseou-se em dados secundários, coletados a partir de pesquisa documental, e dados primários provenientes de entrevistas e questionários, totalizando 49 organizações. 0 modelo estrutura-se em cinco dimensões compostas por 13 elementos. Como contribuições adicionais, apresentam-se uma proposta de definição de Negócios com Impacto Social (NIS) e uma taxonomia, considerando os produtos/serviços, os clientes e a estrutura de lucros.

PALAVRAS-CHAVE | Modelo de negócios, modelo de negócios com impacto social, negócios com impacto social, negócios sociais, negócios inclusivos.

\section{ABSTRACT}

Among the alternatives in the pursuit of sustainable development are businesses with a social impact, i.e., those businesses created to meet some type of social demand via a profitable operation. The aim of this study was to propose a business model with a social impact that can help identifying the elements of such businesses. The business model proposed differs from existing ones in that it combines a number of said models and mainly in that it details the elements that form it. Our method was based on secondary data collected from documentary research, and primary data from interviews and questionnaires, totaling 49 organizations. The model consists of 5 dimensions formed by 13 elements. As additional contributions, we present a proposal for the definition of Businesses with a Social Impact (BSI) and a taxonomy, considering products/services, clients, and profit structure.

KEYWORDS I Business model, business models with a social impact, businesses with a social impact, social businesses, inclusive businesses.

\section{PATRÍCIA SCHERER}

patricia_scherer@hotmail.com Mestre em Administração e Negócios pela Pontifícia Universidade Católica do Rio Grande do Sul, Faculdade de Administração, Contabilidade e Economia - Porto Alegre - RS, Brasil

\section{LÉA BACK}

lea_back@hotmail.com

Mestre em Administração e Negócios pela Pontifícia Universidade Católica do Rio Grande do Sul, Faculdade de Administração, Contabilidade e Economia - Porto Alegre - RS, Brasil

\section{RESUMEN}

Entre las alternativas por la búsqueda del desarrollo sostenible están los negocios con impacto social, o sea, aquellos que son desarrollados para atender a algún tipo de demanda social y con actuación rentable. El objetivo de este estudio fue proponer un modelo de negocios con impacto social que ayude a la identificación de sus elementos. El modelo de negocio propuesto se diferencia de los ya existentes por compilar varios de ellos y, principalmente, por detallar los elementos que lo constituyen. El método de estudio se basó en datos secundarios, recopilados a partir de investigación documental, y datos primarios provenientes de entrevistas y cuestionarios, totalizando 49 organizaciones. El modelo se estructura en cinco dimensiones compuestas por 13 elementos. Como contribuciones adicionales, se presentan una propuesta de definición de Negocios con Impacto Social (NIS) y una taxonomía, considerando los productos/servicios, los clientes y la estructura de lucros.

PALABRAS CLAVE I Modelo de negocios, modelo de negocios con impacto social, negocios con impacto social, negocios sociales, negocios inclusivos. 


\section{INTRODUÇÃO}

No contexto do desenvolvimento sustentável, emerge um novo tipo de organização, que combina dois objetivos anteriormente vistos como incompatíveis: sustentabilidade financeira e geração de valor social (Teodósio \& Comini, 2012; Moura, 2011; Wilson \& Post, 2013). No modelo de negócio, tradicionalmente o foco está voltado à criação de valor econômico para os acionistas. Já nos negócios com impacto social, a criação de valor econômico é vista apenas como uma condição necessária para assegurar a viabilidade financeira (Mair \& Martí, 2006), tendo como finalidade a geração de valor social. Por esse motivo, poucos pesquisadores têm analisado estratégias e modelos de negócio que poderiam ser usados com mais sucesso por esse tipo de negócio (Barki et al., 2015). Para endereçar esse desafio, este artigo buscou identificar, de forma mais detalhada do que as propostas existentes, os elementos constituintes de um modelo de negócio com impacto social.

Para a construção deste modelo, duas bases teóricas são exploradas. A primeira delas aborda definições presentes na literatura sobre negócios com impacto social (Barki et al., 2015), como negócios para a base da pirâmide (Prahalad \& Hart, 2002; Prahalad, 2005; WEF \& BCG, 2009), negócios sociais (Yunus, 2010; Yunus, Moingeon, \& Lehmann-Ortega, 2010; Rahman \& Hussain, 2012) e negócios inclusivos (Marquez, Reficco, \& Berger, WBCSD-SNV; Bonnell \& Veglio, 2011). A segunda trata da conceituação de modelo de negócio e modelo de negócio com impacto social (Osterwalder, 2004; Yunus, Moingeon, \& LehmannOrtega, 2010; Osterwalder \& Pigneur, 2011; Michelini \& Fiorentino, 2012; Stanford, 2014; Burkett, 2013).

Com base na literatura, identifica-se um conjunto inicial de elementos constituintes do modelo. Para validar essa proposta, uma pesquisa foi conduzida em 49 organizações com impacto social cujos dados suportaram a revisita do modelo proposto. Treze elementos foram identificados e organizados em cinco dimensões: (1) rede de parceiros (2) competências da empresa, (3) proposição de valor, (4) a equação do lucro econômico e (5) equação do lucro social.

Por fim, este artigo deixa três contribuições. A primeira delas, a proposição de um modelo de negócios que se difere dos existentes ao identificar, explicar e propor relações entre os 13 elementos constituintes de um modelo de negócio com impacto social, organizados em cinco dimensões. A segunda, uma taxonomia de negócios com impacto social considerando (1) produtos e serviços, (2) tipos de cliente e (3) estrutura de lucros, da qual deriva a terceira contribuição na forma de uma definição de negócios com impacto social (NIS): organizações que visam solucionar demandas relacionadas a problemas sociais, seja ofertando produtos e serviços, seja incluindo indivíduos ou grupos.
Essas organizações devem promover sua própria sustentabilidade financeira, sendo facultativa a distribuição de lucros.

O trabalho apresenta a seguinte estrutura: introdução, referencial teórico, método, proposta de um modelo de negócio com impacto social e considerações finais, sugerindo debates para futuras pesquisas.

\section{REFERENCIAL TEÓRICO}

Este capítulo tem o propósito de indicar as possíveis definições de negócio com impacto social, apresentar os elementos iniciais que compuseram o modelo proposto e apresentar as bases teóricas relativas aos tipos de negócio com impacto social e aos modelos de negócio social.

\section{Negócios com Impacto Social (NIS)}

De acordo com Barki (2015), os chamados negócios sociais emergem a partir da premiação do Nobel da Paz, em 2006, na qual Yunus foi reconhecido pelo seu trabalho sobre microcrédito, buscando a redução da vulnerabilidade dos pobres em Bangladesh. Nesse contexto, emerge um modelo de organização híbrida que combina as competências do setor privado com os conhecimentos de gestão social do Terceiro Setor, com o objetivo de resolver os problemas sociais utilizando os mecanismos de mercado, o que origina os negócios com impacto social, os quais trazem, por vezes, soluções inovadoras aos problemas sociais (Barki, 2014; Wilson \& Post, 2013; Thompson \& Macmillan, 2010).

Ao realizar uma pesquisa sobre os negócios com impacto social ou negócios de impacto, depara-se com um primeiro grande desafio, uma vez que podem ser identificados diferentes termos e nomenclaturas relacionados, como empresa social, negócios para a base da pirâmide (BOP - base of the pyramid), negócios sociais e negócios inclusivos. Uma forma de compreender isso é utilizar uma lente das diferentes perspectivas para definir negócios com impacto social (Comini, Barki, \& Aguiar, 2012). Na perspectiva europeia, o termo preponderante é empresa social, tendo sua origem em cooperativas, com foco na população marginalizada e como complementação dos serviços públicos. Na perspectiva norte-americana, o termo mais utilizado é negócio social particularmente vinculado a estratégias para BoP, podendo ser uma empresa com foco social ou uma unidade de negócio de empresa comercial. Por último, na perspectiva dos países em desenvolvimento, prevalece o termo negócios inclusivos, cuja preocupação central está na redução da pobreza e na inclusão social. De acordo com os autores, na América Latina não há uma preocupação em distinguir os conceitos de negócios sociais e 
negócios inclusivos e, no Brasil, negócio inclusivo seria uma subcategoria de negócio social.

Em uma análise retrospectiva do campo, Barki et al. (2015) trazem quatro questões centrais, sendo a primeira delas a conceituação do tema. Os autores resgatam o conceito de negócio social, empresa social e evidenciam a importância de diferenciar tais negócios dos negócios tradicionais. As próximas subseções buscam esclarecer o que é um negócio com impacto social (NIS).

\section{Negócios para a base da pirâmide}

Desde o artigo seminal de Prahalad e Hart (2002) sobre o potencial de mercado localizado na Base da Pirâmide, o conceito evoluiu para a necessidade de encontrar formas de desenvolver modelos de negócios que ofereçam acesso a produtos e serviços para a população de baixa renda e que ajudem a diminuir o elevado déficit social do mundo (Prahalad, 2005).

Essa discussão ocorreu no momento em que a saturação dos mercados desenvolvidos pressiona as organizações a olhar para a base da pirâmide como uma oportunidade com imenso potencial de crescimento nos próximos anos (Prahalad \& Hart, 2002; Prahalad, 2005). A população mundial de baixa renda representa considerável potencial produtivo e empreendedor, bem como inexplorada demanda por produtos e serviços, representando o surgimento de uma nova classe de consumidores e a principal força para impulsionar o crescimento econômico mundial (WEF, \& BCG, 2009).

Considerando que o poder aquisitivo dessas pessoas é restrito, segundo Prahalad (2005), é necessário ofertar produtos em quantidades menores ou embalagens individuais. Para Anderson e Bilou (2007), se as empresas querem atingir a base da pirâmide, precisam se concentrar na disponibilidade, acessibilidade, aceitabilidade e consciência. Conforme o WEF e BCG (2009), as organizações com foco na base da pirâmide podem utilizar os recursos existentes e a colaboração de diferentes stakeholders, além de contar com a capacidade de parceiros, como o governo, as ONGs e as associações, para atingir seus objetivos. As organizações da sociedade civil e/ou ONGs podem auxiliar como porta-vozes das empresas, levando as novas tecnologias e os produtos/serviços à população, auxiliando-a sobre as formas de consumo e benefícios.

Para Comini, Barki, e Aguiar (2012, p. 386): “[...] a base da pirâmide tem sido um campo fértil para o surgimento de um novo tipo de organização que reúne duas metas previamente vistas como incompatíveis: sustentabilidade financeira e geração de valor social".

Conceitualmente, os negócios para a base da pirâmide contemplam um olhar para possíveis oportunidades geradas para essa população, sendo a sua essência centrada em explorar esse segmento de mercado e fornecer produtos e serviços para esse público-alvo, não tendo como objetivo primeiro o impacto social. Tal efeito pode acontecer, mas é colateral e não essencial. Nesse modelo de negócios, o foco está na maximização dos lucros para empresa e acionistas e os benefícios sociais são consequência da venda de seus produtos/serviços.

\section{Negócios sociais}

O termo negócios sociais surgiu a partir de Muhammad Yunus, professor de economia, ganhador do prêmio Nobel da Paz em 2006, sendo conceituado como:

[...] um empreendimento concebido para resolver um problema social, deve ser autossustentável, ou seja, gerar renda suficiente para cobrir suas próprias despesas. Depois de cobertos os custos e o investimento, toda a receita excedente é reinvestida no negócio social para expansão e melhorias. [...] o retorno do valor investido é devolvido sem juros ou correções. (Yunus, 2010, p. 10).

Enquanto as empresas tradicionais vendem produtos e serviços para gerar receita, sendo movidas pela maximização dos lucros, com o objetivo principal de criar valor para os acionistas, os negócios sociais funcionam para o benefício e atendimento das necessidades sociais (Yunus, Moingeon, \& Lehmann- Ortega, 2010; Rahman \& Hussain, 2012).

De acordo com Wilson e Post (2013, p. 730), um negócio social busca fundir a criação de valor social e a criação de valor econômico em uma mesma estrutura organizacional. É possível acrescentar ainda, segundo Sardana (2013), que a geração de valor social se estende não somente ao consumidor final, mas a todas as partes interessadas - clientes, colaboradores, fornecedores, investidores e sociedade.

Para Yunus, Moingeon, e Lehmann-Ortega (2010), um negócio social, além de cumprir os objetivos sociais, têm de cobrir os custos de operação, pois não depende de doações nem deve ocorrer a retirada de dividendos pelos acionistas/proprietários, sendo os lucros excedentes reinvestidos no negócio.

Em estudos realizados por Michelini e Fiorentino (2012), foi possível identificar que a prática mais consolidada para os negócios sociais vem de empresas que podem gerar um negócio social dentro da empresa tradicional já existente, ou a criação de outra empresa.

Os negócios sociais vêm de uma perspectiva norteamericana, na qual as organizações privadas se dedicam a 
soluções de problemas sociais e são, normalmente, novos negócios de grandes empresas já estabelecidas. Nos países em desenvolvimento, emerge outro tipo de negócio com impacto social chamado de negócios inclusivos, discutido na próxima seção.

\section{Negócios inclusivos}

Segundo Teodósio e Comini (2012), o termo negócios inclusivos ainda é uma expressão incomum no cotidiano brasileiro. Tanto nas empresas brasileiras, quanto nas discussões acadêmicas, o tema é recente e há poucas publicações brasileiras sobre o assunto.

Os negócios inclusivos envolvem a população de baixa renda no processo de desenvolvimento econômico no âmbito da demanda, como clientes e consumidores, e no âmbito da oferta, como empregados, produtores e donos de negócios em vários pontos da cadeia de valor. Eles estabelecem elos entre os negócios e a população, gerando uma relação de benefício mútuo. Para os empresários, eles trazem inovação, criação de novos mercados e fortalecimento de canais de oferta. Para a população de baixa renda, eles geram maior produtividade, rendas sustentáveis e capacitação (UNDP, 2008; Boechat, Rosa, e Oliveira (2010). Marquez, Reficco, e Berger (2009) complementam que a iniciativa leva à transformação do status quo, que é o potencial e a aspiração de transformar positivamente as condições de vida da população de baixa renda.

Esse conceito corrobora com a afirmação de Moura (2011), que diz que o modelo de negócios inclusivos vai além da combinação de sustentabilidade financeira e geração de valor social, pois prevê a efetiva inserção da população de baixa renda no processo produtivo de um negócio e não somente como consumidor final.

Para o WBCSD-SNV (2011), a originalidade dos negócios inclusivos reside em uma visão voltada à diminuição da pobreza e que não contradiz o papel fundamental dos negócios, que é gerar lucros, os quais podem ser distribuídos entre proprietários e acionistas. 0 resultado do modelo, segundo Thompson e Mac Millan (2010), oferece um ponto de encontro, no qual o benefício econômico corporativo e impactos sociais podem ser obtidos simultaneamente.

Esse é um modelo de negócios considerado abrangente, pois pode ser operado tanto fora quanto dentro das comunidades de baixa renda e envolver as pessoas e a comunidade, com o objetivo de superar a pobreza, permitindo-lhes acesso à informação, à educação, à saúde e à comunicação, ou ainda oferecendo bens e serviços de qualidade a preços justos (WBCSDSNV, 2011; Bonnell \& Veglio, 2011).

Teodósio e Comini (2012) destacam que esse modelo se abre como uma oportunidade para aproximar as organizações da sociedade civil, as cooperativas, as empresas de pequeno, médio ou grande porte e o governo para debaterem sobre a contribuição de todos para a desigualdade social e a exclusão da pobreza.

Entre as barreiras que as empresas encontram para o seu desenvolvimento, está a dificuldade para captação de recursos, que é a fonte de financiamento ou capital de risco, podendo comprometer a implementação do negócio. No que tange à população, muitas comunidades não contam com estrutura associativa ou cooperativa, e as pessoas carentes, em sua maioria, também não têm acesso a crédito, o que dificulta que elas possam atuar como fornecedores ou produtores na cadeia de valor de um negócio inclusivo (WBCSD-SNV, 2011).

Por fim, muitas das barreiras identificadas relacionam-se com a forma como a organização é estruturada e com as relações que ela estabelece com o mercado, elementos que são foco do conceito de modelo de negócios, reforçando a importância desta pesquisa em investigar os elementos de um modelo de negócios com impacto social.

\section{Características dos negócios com impacto social}

A partir desta revisão de literatura já se destacam duas contribuições deste artigo: uma definição para negócios com impacto social (NIS) e uma proposta de taxonomia.

Quanto à definição, apesar de crescente o número de artigos sobre o tema e de alguns termos serem mais citados que outros, não se pode afirmar que esses termos tenham uma base conceitual formada e estruturada, com diferentes pontos de vista sobre as características das iniciativas (Barki et al., 2015; Comini, 2011; Tiscoski, Rosolen, \& Comini, 2013). Os NIS caracterizam-se, em geral, por ter como principal propósito atender a interesses sociais, restringindo ou limitando a distribuição de lucros entre os sócios e investidores para reinvestir no próprio objeto socia

Dito isso, passamos a adotar a definição de que NIS são organizações que visam solucionar demandas relacionadas a problemas sociais, seja ofertando produtos e serviços, seja incluindo indivíduos ou grupos. Essas organizações devem promover sua própria sustentabilidade financeira, sendo facultativa a distribuição de lucros.

Inspirados em Comini, Barki, e Aguiar (2012), que apresentam uma análise comparativa entre negócios sociais e negócios tradicionais, buscou-se uma análise comparativa entre os tipos de NIS. Foi possível verificar que os NIS têm algumas particularidades que os diferenciam em relação a elementos como os (1) produtos ou serviços ofertados, (2) os clientes e (3) a estrutura de lucros. O Quadro 1 apresenta a taxonomia proposta baseada nesses três elementos, os quais também emergem para compor o modelo a ser proposto. 
Quadro 1. Taxonomia dos negócios com impacto social

\begin{tabular}{|c|c|c|c|}
\hline \multicolumn{4}{|c|}{ Negócios com impacto social } \\
\hline Clientes & $\begin{array}{l}\text { Exclusivamente para pessoas de baixa } \\
\text { renda. }\end{array}$ & $\begin{array}{l}\text { Preferencialmente pessoas de baixa } \\
\text { renda. }\end{array}$ & $\begin{array}{l}\text { Qualquer cliente: consumidores finais } \\
\text { de qualquer classe social, ou ainda } \\
\text { empresas que adquirem os produtos/ } \\
\text { serviços. }\end{array}$ \\
\hline
\end{tabular}

A próxima subseção trata da segunda base teórica utilizada para a proposição modelo de negócios para NIS.

\section{Modelo de negócios}

Para que as empresas possam sintetizar o pensamento sobre a forma de fazer negócios e levar seus produtos/serviços até o consumidor final, elas necessitam elaborar um modelo de negócios (Zott, Amit, \& Massa, 2011; Lambert \& Davidson, 2013). Diferentes autores apresentam estruturas de modelo de negócios divididas em componentes (Dubosson-Torbay, Osterwalder \& Pigneur, 2002; Chesbrough \& Rosenbloom, 2002). 0 modelo de negócios Canvas detalha mais os componentes e propõe nove blocos de construção para definir os elementos de um modelo de negócios (Figura 1), os quais cobrem as quatro grandes áreas de uma empresa: oferta (proposição de valor), clientes (clientes alvo, canais de distribuição e relacionamento), infraestrutura (atividades chave, recursos e parcerias) e aspectos financeiros - custos e receitas - (Osterwalder, 2004; Osterwalder, Pigneur, \& Tucci, 2005; Osterwalder \& Pigneur, 2009).

Figura 1. Business Model Canvas

\begin{tabular}{|l|l|l|l|l|}
\hline Parceiros-chave & Atividades-chave & \multicolumn{2}{|l|}{ Preposições de Valor } & $\begin{array}{l}\text { Relacionamento } \\
\text { com Clientes }\end{array}$ \\
\cline { 4 - 5 } & \multicolumn{2}{|l|}{$\begin{array}{l}\text { Segmentos de } \\
\text { Clientes }\end{array}$} \\
\cline { 2 - 5 } & Recursos-chave & & Canais \\
\hline Custos & & Receitas & \\
\hline
\end{tabular}

Fonte: Adaptado de Business Model Generation (2013). 


\section{Modelo de negócio com impacto social}

Nos últimos tempos, alguns autores têm utilizado as referências de modelo de negócios tradicionais para analisar aqueles com impacto social. Entretanto, os modelos de negócio tradicionais não respondem às necessidades dos negócios com impacto social, pois não incorporam a geração de valor social (Michelini \& Fiorentino, 2012).

O modelo de negócios Canvas, por exemplo, tem sido usado como base de diferentes propostas: Social Canvas I (Osterwalder \& Pigneur, 2011), Social Canvas II (Stanford, 2014) e Social Canvas III (Burkett, 2013). Os dois primeiros basicamente consideram a incorporação de um bloco denominado proposta de valor social. No Social Canvas III, Burkett (2013) propõe o uso do modelo de negócios do Canvas, usando os mesmos elementos do modelo tradicional, com duas trajetórias diferentes, uma para o impacto social e outra para o comércio tradicional. Essas proposições diferem muito pouco do Canvas tradicional.

Segundo Yunus, Moingeon, e Lehmann-Ortega (2010), o modelo de negócios convencional tem três componentes: (1) proposição de valor, (2) constelação de valor e (3) equação de lucro econômico. Para adaptar o modelo tradicional à proposta dos modelos de negócio com impacto social, os autores adicionam um quarto elemento, a equação de lucro social, explicitando que a proposta de valor e a constelação de valor não são focadas exclusivamente no cliente, pois abrangem todos os stakeholders. Para os autores, a equação de lucro econômico visa, apenas, à recuperação completa de custos e de capital (essa situação aplica-se somente aos negócios sociais, na visão de Yunus, e não aos negócios de impacto social de forma geral).
As autoras Michelini e Fiorentino (2012) utilizaram os conceitos do modelo de negócios Canvas (Osterwalder, 2004) e do modelo de negócios sociais proposto por Yunus, Moingeon e Lehmann-Ortega (2010) e apresentaram um quadro de análise para verificar as semelhanças e diferenças dos negócios sociais e dos negócios inclusivos. 0 modelo apresenta quatro áreas: oferta (proposta de valor), mercado (segmento de mercado e distribuição), ecossistema (modelo de governança, cadeia de valor, competências e rede de parceiros) e características econômicas (gestão de receitas).

A partir da revisão da literatura sobre os NIS e as características dos modelos de negócio, propõe-se o modelo de negócios, objeto deste artigo.

\section{Proposta de um modelo de negócios para NIS}

O modelo de negócios proposto (Figura 2) estrutura-se em cinco dimensões: (1) rede de parceiros (contemplando fornecedores e outras alianças externas para a constituição e manutenção do negócio), (2) competências da empresa (considerando atividades e recursos chave), (3) proposição de valor (a partir da identificação de que produto/serviço é ofertado e o grupo de clientes atendido), (4) equação de lucro econômico, refere-se às receitas geradas e (5) equação do lucro social, representando os elementos responsáveis por gerar os impactos sociais (benefícios sociais gerados e os impactados gerados por eles). As três primeiras dimensões formam a base dos principais elementos que constituem a estrutura e a operação de uma organização.

\section{Figura 2. Modelo de negócios com impacto social}

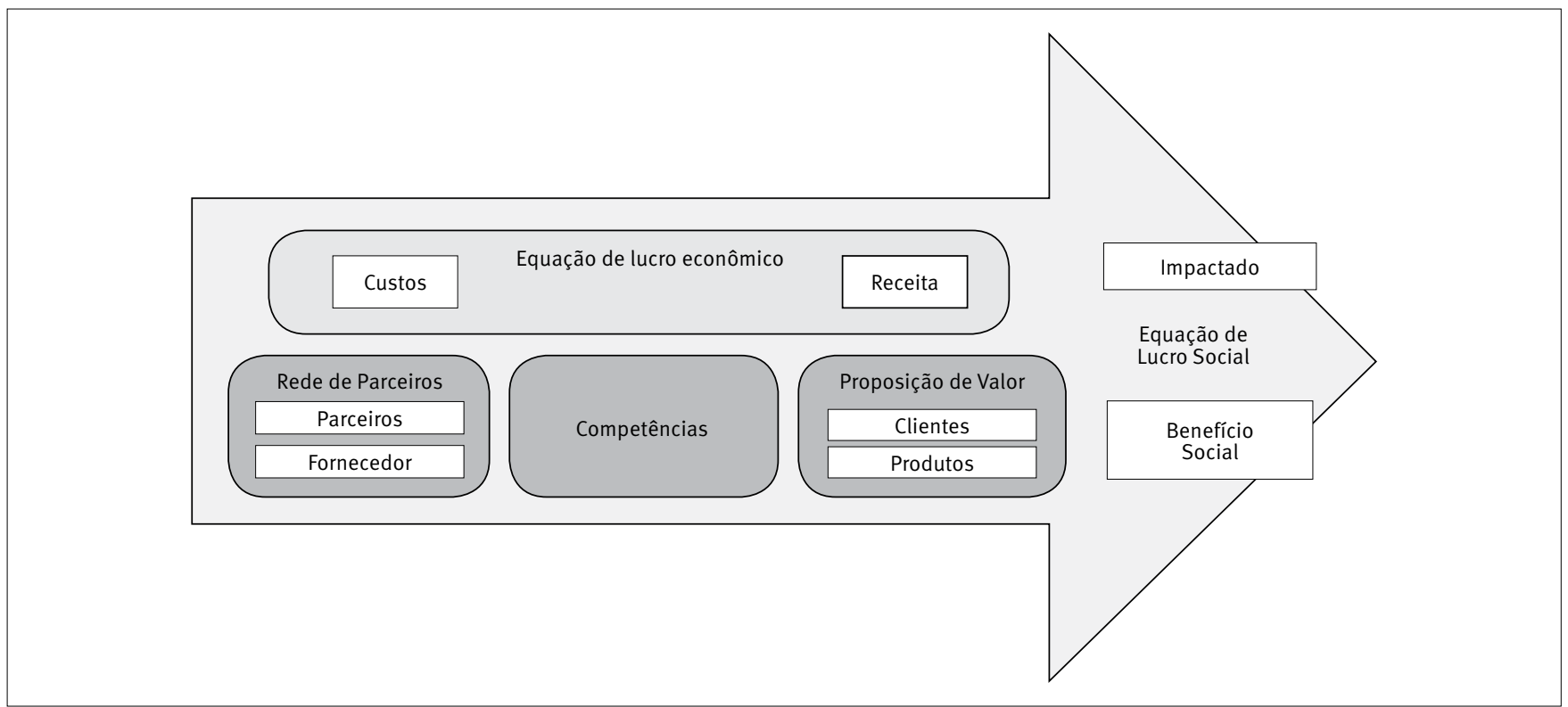


O modelo de negócios proposto diferencia-se dos revisitados na literatura por detalhar, reorganizar e agregar mais elementos constituintes de um modelo de negócio com impacto social. Sob olhar do modelo Canvas, elementos sociais são adicionados e/ ou uma nova leitura é feita em relação a eles. Sob o olhar do modelo proposto por Yunus, Moingeon, e Lehmann-Ortega (2010), emprestou-se a nomenclatura de alguns componentes, alterando e aprofundando a estrutura inicialmente proposta pelos autores.

O Quadro 2 indica as origens das dimensões e elementos, descrevendo-os na terceira coluna.

\section{Quadro 2. Origem e descrição das dimensões e elementos}

\begin{tabular}{|c|c|c|}
\hline Dimensão e Elementos & Origem & Descrição \\
\hline $\begin{array}{l}\text { Rede de parceiros } \\
\text { - Parceiros } \\
\text { - Fornecedores }\end{array}$ & $\begin{array}{l}\text { Infraestrutura - parceiros (Osterwalder, } \\
\text { 2004; Osterwalder, Pigneur, \& Tucci, 2005; } \\
\text { Osterwalder \& Pigneur, 2009). } \\
\text { Constelação de valor - cadeia externa } \\
\text { relativa a rede de parceiros (Yunus, } \\
\text { Moingeon, \& Lehmann-Ortega, 2010). } \\
\text { Ecossistema - cadeia de valor e rede de } \\
\text { parceiros (Michelini \& Fiorentino, 2012). }\end{array}$ & $\begin{array}{l}\text { Os parceiros podem ser as associações e cooperativas, que possam auxiliar } \\
\text { na inserção da empresa ou de um produto em comunidades, atuando como } \\
\text { intermediadores entre a empresa e a população de baixa renda ou a comunidade. } \\
\text { Como parceiros incluem-se as aceleradoras e incubadoras. } \\
\text { Os fornecedores são aqueles que fornecem a matéria-prima ou mão de obra } \\
\text { para o desenvolvimento dos produtos ou serviços. Eles podem ser empresas } \\
\text { privadas, agricultores, bem como produtores locais. Os negócios inclusivos têm } \\
\text { como princípio beneficiar ou estimular a inserção das classes C, D e E como } \\
\text { fornecedores ou donos de negócio que forneçam matéria-prima. }\end{array}$ \\
\hline Competências & $\begin{array}{l}\text { Infraestrutura - atividades e recursos chave } \\
\text { (Osterwalder, 2004; Osterwalder, Pigneur, \& } \\
\text { Tucci, 2005; Osterwalder \& Pigneur, 2009). } \\
\text { Constelacao de valor - cadeia interna } \\
\text { as competencias da empresa (Yunus, } \\
\text { Moingeon, \& Lehmann-Ortega, 2010). } \\
\text { Ecossistema - competencias (Michelini \& } \\
\text { Fiorentino, 2012). }\end{array}$ & $\begin{array}{l}\text { Esta dimensão objetiva identificar os conhecimentos organizacionais que são } \\
\text { necessários para o estabelecimento do negócio, especificando um intervalo de } \\
\text { proficiências, conhecimento e habilidades da organização. }\end{array}$ \\
\hline $\begin{array}{l}\text { Proposição de valor } \\
\text { - Clientes } \\
\text { - Produtos }\end{array}$ & $\begin{array}{l}\text { Oferta e Clientes (Osterwalder, 2004; } \\
\text { Osterwalder, Pigneur, \& Tucci, 2005; } \\
\text { Osterwalder \& Pigneur, 2009). } \\
\text { Proposta de valor (Yunus, Moingeon, \& } \\
\text { Lehmann-Ortega, 2010). } \\
\text { Proposta de valor e Mercado (Michelini \& } \\
\text { Fiorentino, 2012). }\end{array}$ & $\begin{array}{l}\text { Concentra o aspecto voltado para o mercado e o público consumidor, onde os } \\
\text { clientes podem ser pessoas de qualquer classe econômica, outras empresas ou } \\
\text { portadores de necessidades especiais. } \\
\text { O produto ou serviço ofertado que pode ser vendido diretamente à população } \\
\text { de baixa renda ou ainda ser vendido a outras classes econômicas ou empresas, } \\
\text { mas produzido por pessoas de baixa renda, sendo uma solução para um } \\
\text { problema social uma vez que traz como resultado a geração de renda (exemplo } \\
\text { dos negócios inclusivos). }\end{array}$ \\
\hline $\begin{array}{l}\text { Equação de lucro } \\
\text { econômico } \\
\text { - Custos } \\
\text { - Receita }\end{array}$ & $\begin{array}{l}\text { Aspectos Financeiros (Osterwalder, 2004; } \\
\text { Osterwalder, Pigneur, \& Tucci, 2005; } \\
\text { Osterwalder \& Pigneur, 2009). } \\
\text { Equacao de lucro economico (Yunus, } \\
\text { Moingeon, \& Lehmann-Ortega, 2010). } \\
\text { Aspectos Financeiros (Michelini \& } \\
\text { Fiorentino, 2012). }\end{array}$ & $\begin{array}{l}\text { A estrutura de custos resume as consequências monetárias dos } \\
\text { meios utilizados pela empresa para operar o modelo de negócios. } \\
\text { O modelo de receita descreve a forma como uma empresa ganha dinheiro } \\
\text { através das fontes de geração de receita do negócio. }\end{array}$ \\
\hline $\begin{array}{l}\text { Equação do lucro social } \\
\text { - Impactado } \\
\text { - Benefício social }\end{array}$ & $\begin{array}{l}\text { Equação de lucro social (Yunus, Moingeon, } \\
\text { \& Lehmann-Ortega, 2010). } \\
\text { Esta dimensão e a menos explicitada } \\
\text { nos modelos revisitados, sendo uma } \\
\text { contribuição desta proposta dar destaque } \\
\text { a tais elementos. }\end{array}$ & $\begin{array}{l}\text { O impactado representa o público que recebe o benefício, identificando se } \\
\text { ele é impactado como cliente, se o impactado encontra-se na comunidade } \\
\text { (geração de renda ou emprego), podem ser impactados ainda os portadores de } \\
\text { necessidades especiais ou o meio ambiente. } \\
\text { O benefício social é o benefício que o negócio proporciona, podendo ser social } \\
\text { ou ambiental. O indicador de que benefícios sociais um modelo de negócio gera } \\
\text { é importante para a empresa saber se está atingindo os objetivos propostos } \\
\text { quando da abertura do negócio, e também para investidores interessados em } \\
\text { apoiar iniciativas com de impacto social. } \\
\text { Para a classificação desses benefícios sociais, a referência a ser utilizada possui } \\
\text { base nos indicadores propostos pelo IRIS (2014) - um catálogo internacional de } \\
\text { métricas de desempenho utilizado pelos principais investidores em negócios } \\
\text { geradores de impacto social, para medir o sucesso ambiental, social e/ou } \\
\text { financeiro de um negócio. }\end{array}$ \\
\hline
\end{tabular}




\section{MÉTODO}

Com o objetivo de validar e enriquecer o modelo proposto, foi realizada uma incursão ao campo de investigação, a qual se baseou em dados secundários e primários. Os dados secundários foram coletados a partir de pesquisa documental enquanto os primários tiveram como instrumentos de coleta entrevistas e questionários. Na Figura 3, descreve-se o desenho de pesquisa.

\section{Figura 3. Desenho de Pesquisa}

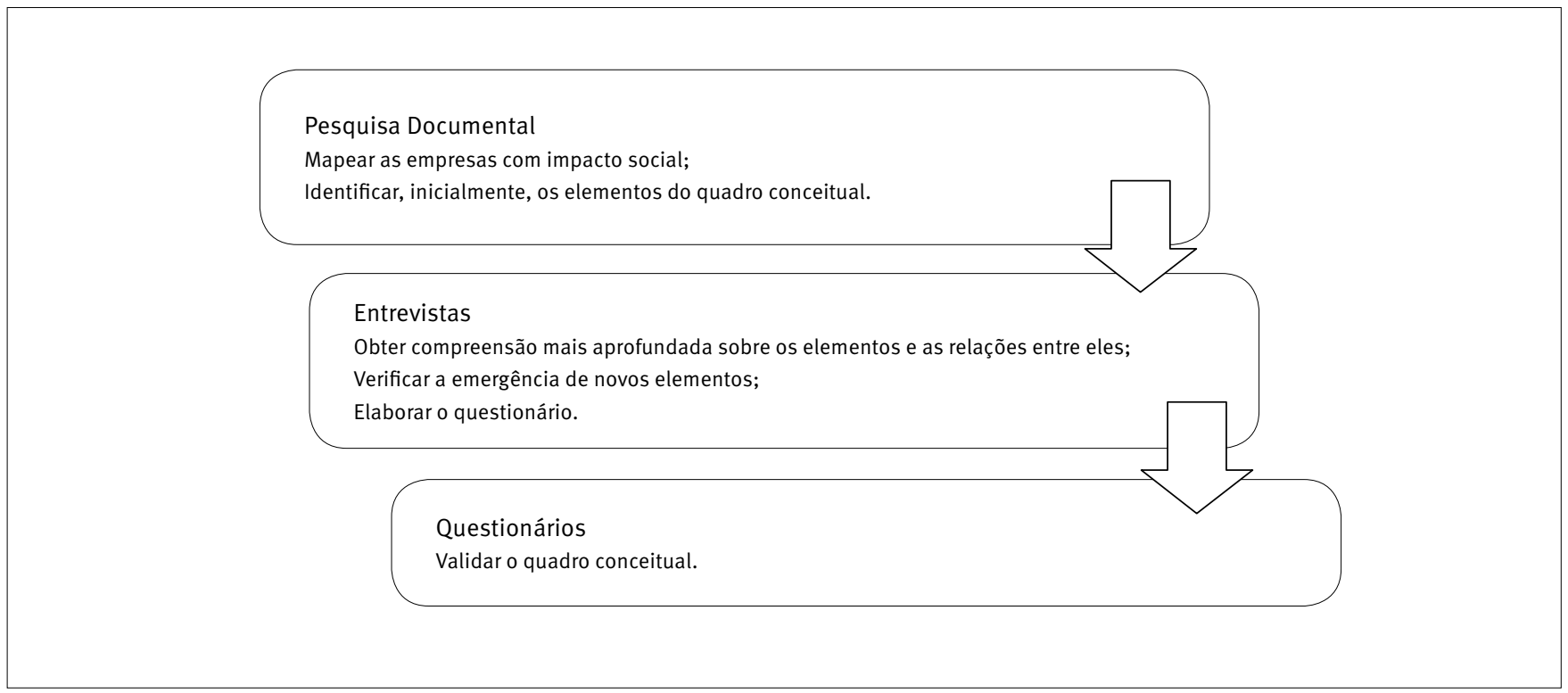

\section{Pesquisa documental}

Optou-se por iniciar a fase de levantamento do campo dos negócios com impacto social pela aceleradora de negócios Artemísia, por ser pioneira na disseminação e no fomento de negócios de impacto social no Brasil, em que atua, inicialmente, no desenvolvimento de startups e, então, estrutura a aceleradora. A Artemísia (2014) acompanhou o surgimento dos primeiros fundos de investimento de impacto brasileiros e o nascimento de novas incubadoras e aceleradoras. A partir de uma lista inicial de 34 iniciativas aceleradas por ela, utilizou-se a técnica “Bola de Neve" para auxiliar na pesquisa. A técnica consiste em escolher inicialmente uma determinada amostra. Aos indivíduos da amostra inicial, são solicitados que indiquem outras pessoas. Essas indicações vão sendo coletadas até que se alcance o ponto de saturação (Goodman, 1961). Da lista inicial de 34 iniciativas, visitou-se o site de cada uma delas objetivando identificar outros negócios e/ou parceiros da iniciativa. Esses parceiros eram consultados para verificar se eles disponibilizariam seu portfólio de empresas apoiadas. Em caso positivo, eram adicionadas à lista de iniciativas inicialmente composta pelas 34 empresas aceleradas pela Artemísia. Assim, foram feitos os levantamentos até que as empresas e nomes constantes começaram a se repetir, chegando-se ao ponto de saturação. No total foram investigados os sites de dez parceiros de negócio, resultando em 213 iniciativas de impacto social.

Para cada uma das empresas identificadas no mapeamento, foi adotado o mesmo critério: acesso ao home site oficial da empresa para buscar os dados de contato, informações relativas à estrutura da empresa, ramo de atividade, público-alvo, quem são os clientes, rede de parceiros e abrangência do negócio. No caso de empresas que não têm site, foi pesquisado se elas tinham blog ou página em rede. Após o término do levantamento de dados secundários, foram descartadas iniciativas que não atendiam aos requisitos desta pesquisa, como ONGs, e as que não foram localizados os dados para contato, restando 99 empresas válidas.

\section{Entrevistas}

As entrevistas foram conduzidas a partir de um roteiro semiestruturado de questões e o seguinte protocolo foi seguido. Para as empresas que disponibilizaram em seu site o e-mail para contato, foi encaminhada uma mensagem com a apresentação da pesquisa e a solicitação de agendamento da entrevista por telefone ou skype. Para as empresas que não haviam fornecido endereço de e-mail, o contato foi feito por telefone, oportunidade 
em que foram solicitados o e-mail para o envio da apresentação da pesquisa e o agendamento para entrevista. Finalmente, para as empresas em que não foi possível obter nenhum contato, mas apresentavam o link do "Fale conosco", o início da comunicação foi feito por essa ferramenta, solicitando-se um e-mail para maior detalhamento da pesquisa. Disponibilizaram-se para a entrevista seis empreendedores (quadro 3). 0 período de entrevistas ocorreu entre 17 e 31 de junho de 2014, cada uma teve duração média de 30 minutos e os respondentes eram os fundadores ou sócios.

As entrevistas permitiram detalhar os elementos, a exemplo da dimensão competência, na qual as perguntas especificaram questões como: Na época da abertura do negócio, quais eram os conhecimentos prévios do empreendedor? Existia conhecimento do território ou da comunidade a serem atendidos? 0 modelo de negócios era familiar? Qual o papel das pessoas nas atividades de produção, distribuição e/ou vendas do produto/serviço? Para cada uma delas era sempre questionado o "como" ou "por quê". Além do detalhamento, emergiram relações, como na dimensão equação do lucro econômico, em que as questões investigaram o destino das receitas e dos lucros (exemplo: dividido entre acionistas, dividido entre funcionários, para pagamento de investidores...). Todos os elementos ou relações foram incorporados no questionário.

\section{Quadro 3. Perfil das empresas entrevistadas}

\begin{tabular}{|c|c|c|c|}
\hline Empresa & Região & Setor & Produto que oferta \\
\hline Empresa A & PR & $\begin{array}{l}\text { Tecnologias } \\
\text { inclusivas }\end{array}$ & $\begin{array}{l}\text { Software de baixo custo e alta eficiência, que possibilita o acesso a informação e } \\
\text { educação às pessoas com deficiência visual. }\end{array}$ \\
\hline Empresa B & SP & Saúde & $\begin{array}{l}\text { Tratamento e prevenção de obesidade infantil; atua em diversas frentes para levar a } \\
\text { mudança comportamental aos obesos. }\end{array}$ \\
\hline Empresa C & SP & Habitação & Soluções integradas em reformas habitacionais de baixo custo. \\
\hline Empresa D & SP & Serviços & Realiza serviços de entregas expressas utilizando somente bicicletas. \\
\hline Empresa E & MG & $\begin{array}{l}\text { Tecnologias } \\
\text { inclusivas }\end{array}$ & $\begin{array}{l}\text { Soluções inovadoras e com tecnologia de ponta de produtos e serviços visando a } \\
\text { integração da população com deficiência junto a sociedade (LIBRAS). }\end{array}$ \\
\hline Empresa F & MT & $\begin{array}{l}\text { Bens de } \\
\text { consumo }\end{array}$ & Produtos derivados da Castanha do Pará (com e sem casca, azeite, creme e granulados). \\
\hline
\end{tabular}

\section{Questionários}

Considerando que 16 empresas não responderam ao contato do "Fale conosco", ou seja, não disponibilizaram um e-mail para o envio do instrumento de coleta de dados, e em outras seis os dados foram coletados a partir das entrevistas, restaram 77 empresas válidas para a aplicação dos questionários (Figura 4).

Figura 4. Amostra para a realização dos questionários

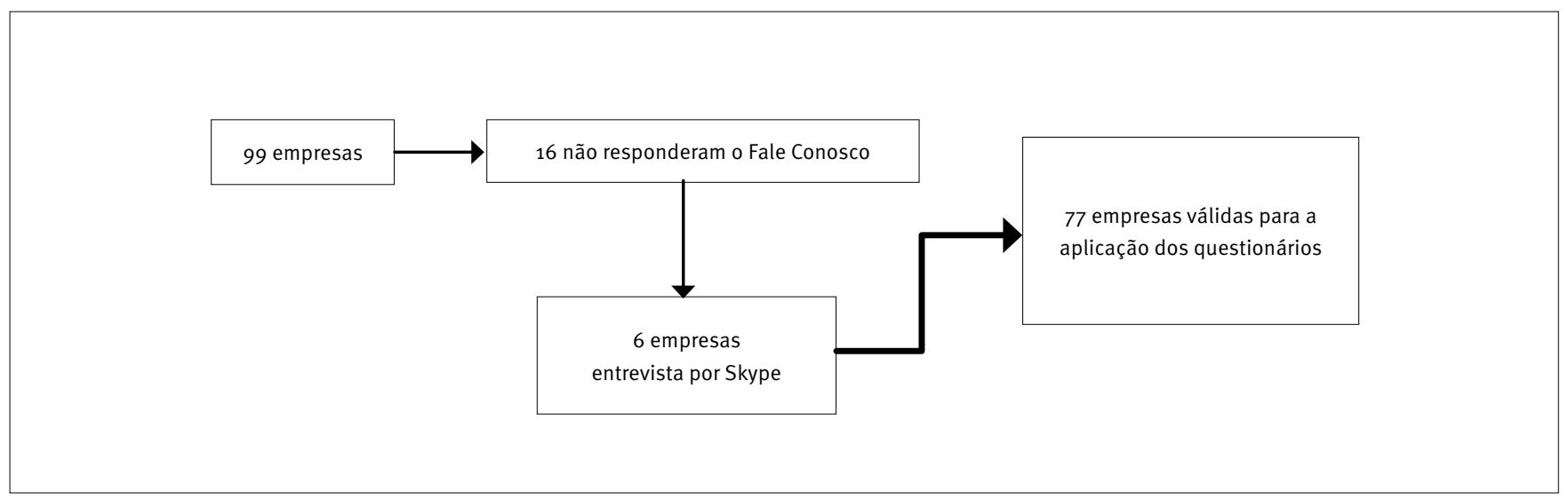


O questionário foi encaminhado via correio eletrônico às 77 empresas e 43 responderam a ele. 0 período de envio ocorreu entre julho e agosto/2014. A caracterização por região e setor de atuação dos respondentes é ilustrada na Figura 5 .

Figura 5. Caracterização dos respondentes do questionário: Por setor e região do Brasil

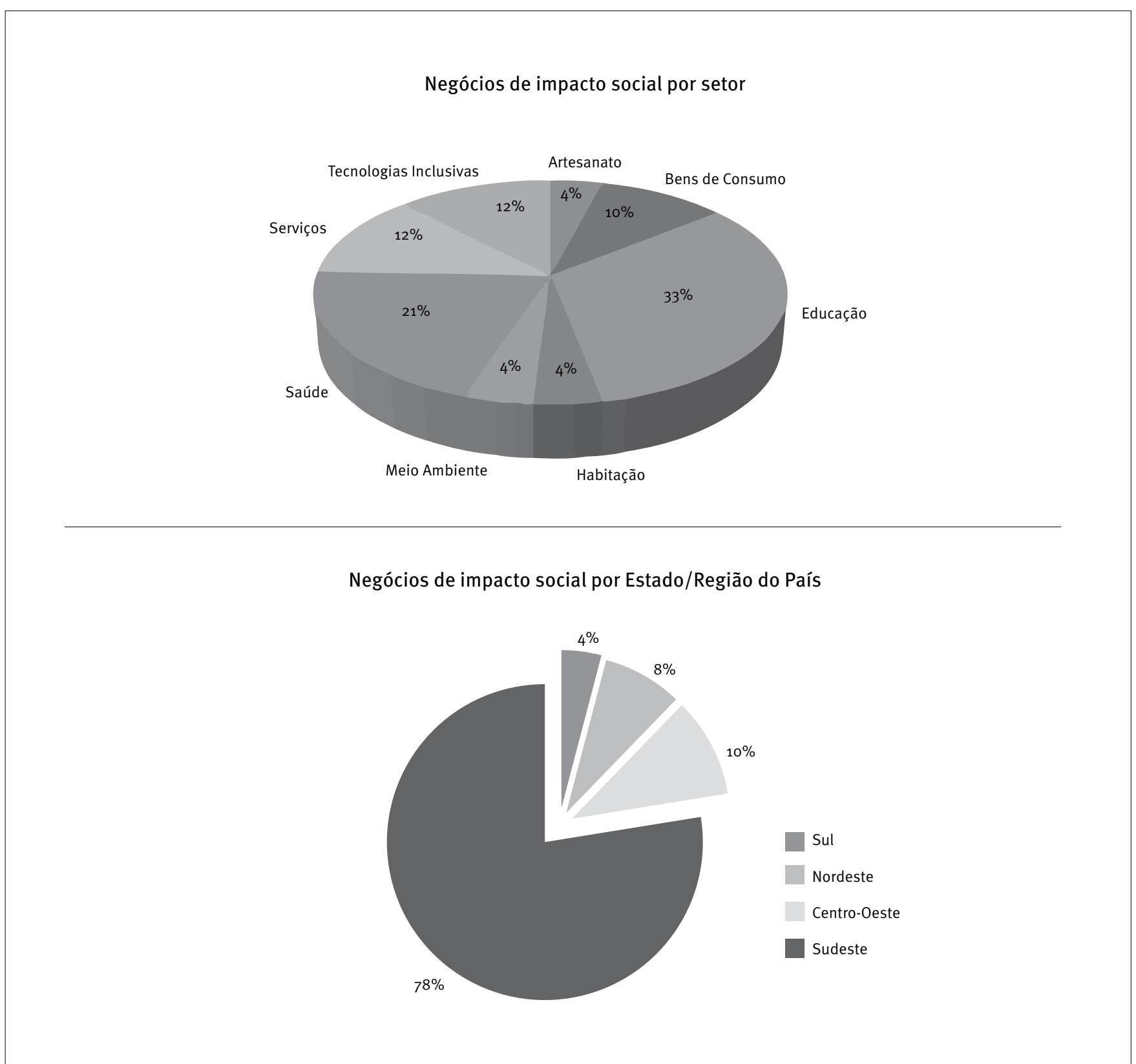

Na sequência, foram acrescidos os dados das seis empresas entrevistadas, totalizando 49 organizações com impacto social, cujos dados suportaram a revisita ao modelo de negócios proposto.

\section{RESULTADOS: UM MODELO DE NEGÓCIOS PARA NIS}

A partir da análise dos dados coletados foi possível não somente aumentar a compreensão em relação aos elementos propostos incialmente, como também discriminar novos elementos e identificar relações entre eles (Figura 6). 
Figura 6. Modelo de negócios com impacto social revisitado

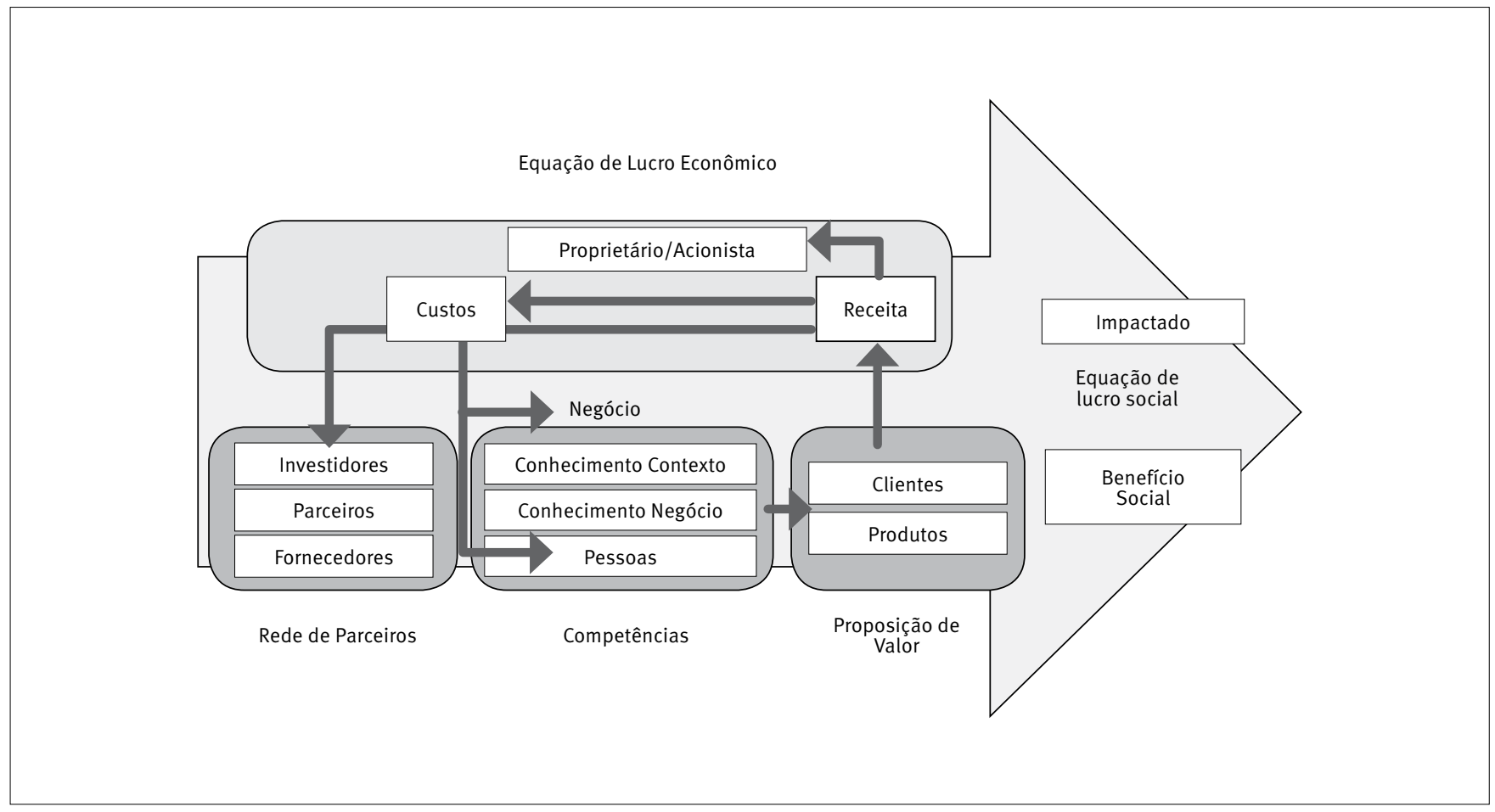

O quadro manteve a mesma estrutura de cinco dimensões, em que as modificações aconteceram na (1) rede de parceiros, com a inclusão do elemento investidores, nas (2) competências, com o detalhamento das competências sob as lentes das pessoas e do conhecimento sobre o negócio, e na (4) equação do lucro econômico, com o detalhamento das relações de distribuição de lucros. Seguem o detalhamento dos novos elementos e relações, bem como os dados de campo que reforçam o modelo.

\section{Rede de parceiros}

A rede de parceiros é formada por três elementos: investidores, fornecedores e parceiros.

Os investidores são pessoas ou entidades que apoiam e financiam iniciativas que geram impactos sociais. Os investidores de impacto podem ser entendidos como atores do conceito de Venture Philanthropy (Filantropia de Risco), uma alternativa à filantropia tradicional, no formato de doações, buscando o desenvolvimento de modelos de negócios sociais sustentáveis no longo prazo. Para Letts, Ryan, e Grossman (1997), Venture Philanthropy é a aplicação dos princípios de Venture Capital (Capital de Risco) em benefício da filantropia tradicional. Dessa forma, os investidores de impacto buscam ir além do aporte financeiro para infraestrutura organizacional, abarcando questões de gestão e governança, envolvendo-se na discussão de estratégias e metas dos negócios com impacto social (Slyke \& Newman, 2006).

Mais da metade dos empreendedores (56\%) conta com algum tipo de capital de terceiros para iniciar o negócio. A origem do recurso externo tem quatro grandes atores entre as organizações investigadas: fundos de investimentos em empresas com impacto social, investidores anjo, bancos (o empresário buscou financiamento diretamente) e recursos de projetos do governo. Foi possível encontrar casos em que os investidores participam das decisões estratégicas nos empreendimentos. $\mathrm{Na}$ visão dos entrevistados, os investidores são fundamentais para abrir ou expandir uma iniciativa. Esses resultados demonstram a importância dos investidores no ecossistema dos negócios com impacto social, por isso a sua inclusão no quadro proposto. Tiscoski, Rosolen, e Comini (2013) ressaltam o crescimento de fundos de investimentos voltados para esse tipo de empreendimento.

Quanto aos fornecedores, mesmo os negócios inclusivos tendo como princípio estimular a inserção das classes $C$, D e E como fornecedores, observou-se que a maioria dos negócios ( $71 \%$ ) se utiliza de mão de obra especializada para a oferta de seus serviços ou desenvolvimento de seus produtos, sendo somente $29 \%$ dos fornecedores artesãos, produtores rurais ou população de baixa renda.

Quanto aos parceiros, 40 empresas (82\%) declararam ter parceiros de negócio, recebendo destaque as aceleradoras 
e os parceiros de apoio e consultoria, sendo que quatro empreendedores (10\%) passaram por mais de um processo de aceleração. Observou-se que 35 delas (88\%) contaram com esse tipo de parceria para o desenvolvimento ou crescimento do negócio. A Artemísia foi a aceleradora de maior destaque (65\% das empresas que foram aceleradas), seguida pelo Projeto Visão de Sucesso, Instituto Quintessa e Pipa. Quanto aos parceiros de apoio e consultoria, destacam-se as universidades e incubadoras que deram apoio a $35 \%$ dos empreendedores. 0 número citado de apoiadores e empresas de consultoria mostra o quão presente essas iniciativas se fazem para a abertura de novos negócios, bem como para seu desenvolvimento e sua consolidação.

\section{Competências}

Esta dimensão é constituída por elementos que representam os conhecimentos organizacionais necessários à abertura do negócio e o papel das pessoas em sua operação.

O primeiro elemento, denominado conhecimento do contexto local, refere-se ao grau de informação sobre o território ou a comunidade atendida. Os empreendedores afirmam em $72 \%$ dos casos que tinham conhecimento prévio do contexto local, por já terem experiência em empresas nas quais trabalhavam antes de empreender um negócio de impacto: “[...] os empreendedores já desenvolviam atividades semelhantes em outra organização. Tinham conhecimento do setor e dos clientes".

O conhecimento no negócio, segundo elemento, que envolve a experiência e o domínio dos processos de produção e/ou do serviço a ser prestado, foi identificado em $51 \%$ dos respondentes, como ilustrado nesta fala: “Já tínhamos uma clínica que atendia ao público das classes $A B$, mas frequentemente atendia a pacientes das classes CDE que não podiam pagar. Foi aí que surgiu a ideia...".

0 terceiro elemento, as pessoas, refere-se ao quanto o negócio depende do papel das pessoas como especialistas na operação. Somente 33\% das iniciativas tinham seus recursos essenciais dirigidos às pessoas. A maioria delas tinha como recurso interno pessoas com especialidades técnicas no desenvolvimento de software.

Apenas $10 \%$ tiveram todas as competências assinaladas com sim, ou seja, com conhecimento do contexto local, do negócio e também dos recursos essenciais ligados às pessoas.

O detalhamento das competências pode tornar-se fundamental para a continuidade do negócio. Por exemplo, na concepção de modelo de negócios com impacto social, pode-se identificar alguma deficiência em alguns dos conhecimentos, mas não evidenciar um diferencial ligado às pessoas envolvidas no processo de produção, distribuição e/ou nas vendas do produto/ serviço.

\section{Proposição de valor}

A proposição de valor é composta por dois elementos: produto/ serviço ofertado e clientes.

Foram identificados produtos bastante diversificados como artesanato, bens de consumo, serviços (exemplo: office boy), cursos on-line e preparatórios para provas, serviços habitacionais de reforma de baixo custo, consultas e exames médicos, tecnologias inclusivas para portadores de necessidades especiais. A maioria dos exemplos destina-se à população de baixa renda, entretanto, no setor de artesanato, bens de consumo e serviços, identifica-se que o produto ou serviço tem clientes diversos, sendo a caracterização do negócio de impacto não pelo que oferta, mas sim pela inclusão da comunidade na prestação do serviço ou produto.

Em relação aos clientes, foram identificados quatro grupos, não excludentes entre si: população de baixa renda, classes $A$ e $B$, empresas e portadores de necessidades especiais (PNE). 0 total de iniciativas que tem como clientes a população de baixa renda soma 28 iniciativas, representando 57\% dos negócios em estudo: 33\% das iniciativas atendem exclusivamente à população de baixa renda, outras dez iniciativas acolhem, além da população de baixa renda, as classes A e B, e duas iniciativas atendem também a empresas. Oito iniciativas (16\%) ofertam exclusivamente a outras empresas. Duas iniciativas atendem a empresas e classes A e B. Três iniciativas (6\%) acolhem exclusivamente classes $A$ e $B$, e seis negócios (12\%) o PNE.

\section{Equação de lucro econômico}

Representa os aspectos financeiros do negócio, receitas e custos, e evidencia as possíveis relações quanto à distribuição de lucros.

Oito empresas não quiseram revelar o destino dos excedentes provenientes das receitas, ou seja, a base de análise foi feita em 41 empresas. Quinze empresas (37\%) pagam prólabore a seus empreendedores, e os lucros excedentes são totalmente reinvestidos no negócio. As outras 26 iniciativas (63\%) pagam pró-labore aos empreendedores e reinvestem parte do lucro na empresa.

Das 26 empresas que reinvestem parcialmente os excedentes, a parcela do lucro não reinvestido é utilizada em 21 delas (51\%), remunerando somente os proprietários/acionistas; três empresas (7\%) afirmam pagar retorno aos investidores (há casos em que os investidores somente recebem o retorno do capital investido, 
e outros que têm participação nos lucros); duas empresas (5\%) destacam que há distribuição dos lucros entre os funcionários.

Esses resultados evidenciam uma discussão em torno dos negócios com impacto social. Por um lado, a perspectiva defendida por Yunus (2010) de que todos os lucros deveriam ser reinvestidos na organização. Por outro, a perspectiva que defende a distribuição de dividendos como um mecanismo de atrair investimentos e ter maior impacto (Chu, 2007). É justamente essa perspectiva que norteia as empresas que distribuem o lucro aos investidores. Os respondentes entendem que está na essência do investidor esperar pelo retorno do investimento, ressaltando que são poucos os fundos de investimento social cuja natureza não prevê essa expectativa. Para o negócio crescer e ganhar escala, é essencial captar mais investidores e, muitas vezes, de maior porte do que os iniciais.

\section{Equação de lucro social}

A equação de lucro social compreende dois elementos: os impactados com o negócio e o benefício social gerado. 0 primeiro elemento identifica os atores que recebem o benefício. Foram identificados quatro grupos: a população de baixa renda no papel de clientes, a comunidade, através da geração de renda ou de emprego, os portadores de necessidades especiais (PNE) ou, ainda, o meio ambiente.

O número total de iniciativas que impactaram a população como cliente é $66 \%$. A comunidade é impactada, na geração de emprego e renda, ou com desenvolvimento comunitário por $11 \%$ das empresas. Também foi possível identificar que 9\% impactaram, além da comunidade, o meio ambiente. Já os portadores de necessidades especiais representaram $14 \%$ das empresas estudadas.

Algumas empresas acabam por gerar mais de um tipo de impacto, a exemplo de uma iniciativa voltada para o setor de habitação. 0 produto final é destinado à população de baixa renda (impacto nos clientes), os pedreiros contratados para executar as obras pertencem à comunidade e os materiais para a construção são comprados de empresas da comunidade (impacto na comunidade: gerando emprego e renda).

O benefício social, segundo elemento, é a melhoria que o negócio proporciona, tanto no aspecto social quanto no ambiental. Para a classificação desses benefícios sociais, a referência a ser utilizada é proposta com base nos indicadores do IRIS (2014). Os números encontrados demonstram que a maioria das empresas deste estudo tem o foco de geração de benefícios voltados ao acesso à educação, à saúde, à informação e à tecnologia (Figura 7). Observa-se que o número de benefícios é superior ao de empresas em análise, pois em várias iniciativas é possível identificar mais de uma benfeitoria gerada pelo modelo de negócio. Por exemplo, uma das organizações presta consultoria em TI (capacitam jovens em informática básica e também para o desenvolvimento de aplicativos simples para venda), gerando quatro benefícios: (1) acesso à educação, (2) acesso à informação ou à tecnologia, (3) capacitação e (4) geração de renda.

\section{Figura 7. Benefícios sociais gerados}

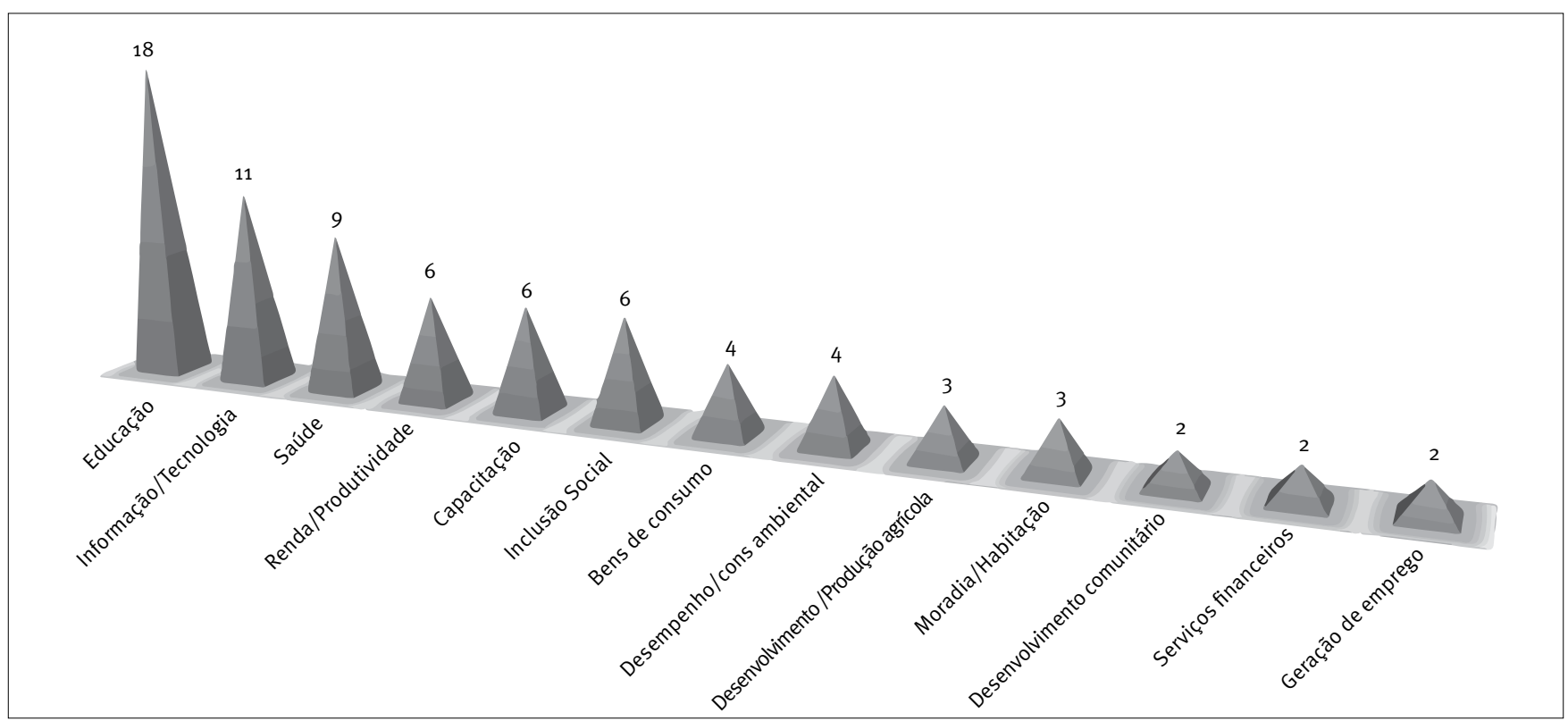


Uma das principais questões relativas aos NIS reside em como medir o impacto social, sendo mais fácil avaliar os outputs - resultados imediatos dos programas implementados, do que os outcomes - resultados de médio prazo que impactaram as condições de vida da população alvo (Barki et al., 2015). Um terceiro tipo de resultado é o impacto propriamente dito, o qual se refere a mudanças de longo prazo nas condições de vida da população alvo que podem ser atribuídas unicamente aos programas implementados. Essa pesquisa não teve como objetivo medir o resultado social, seja ele na forma de output, outcome ou impacto, mas identificar os tipos de benefício gerados. Entretanto, é possível realizar algumas análises interessantes. 0 produto de um dos negócios é um buscador gratuito de informações sobre a rede pública de saúde, o que traz como benefícios acesso à saúde e à informação/tecnologia. Tais benefícios podem estar em diferentes tipos de resultado: o acesso à saúde pode ser considerado um outcome, com potencial para gerar impacto, enquanto o acesso à informação/tecnologia é um output. Outras organizações, uma cujo produto são consultas médicas a baixo custo para a terceira idade, outra o ensino de idiomas a preços acessíveis, apresentam somente resultados considerados output, por serem imediatos e diretos do negócio. Ou seja, é possível perceber os diferentes tipos de resultado nas organizações pesquisadas, como também mais de um tipo em uma única organização.

Analisando-se a relação entre os benefícios sociais e os impactados (Quadro 4) identifica-se que os benefícios sociais de acesso à educação e à informação/tecnologia são os que contam com mais grupos impactados. Nesta análise, evidencia-se novamente a existência dos três tipos de resultado, motivo pelo qual os respondentes associam mais de um impactado. Por exemplo, nos benefícios em que os impactados são os clientes e a comunidade, eles podem ser relacionados a outputs e outcomes, respectivamente.

Quadro 4. Benefícios sociais e impactados

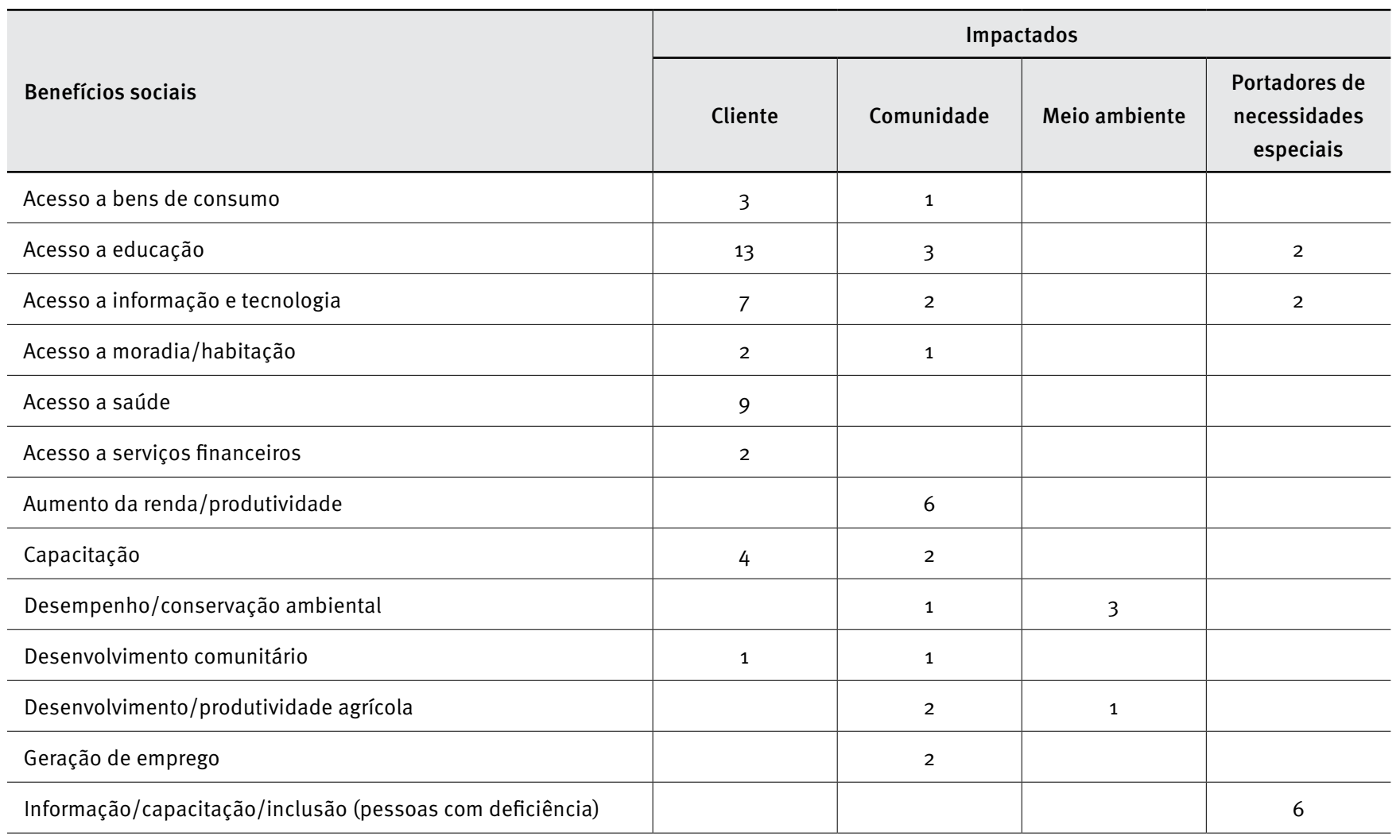

Observa-se também que, na percepção dos respondentes, existem diferentes abrangências. Quando o benefício social é o acesso a saúde ou a serviços financeiros, o impactado é somente sentido na população de baixa renda no papel de cliente (menor abrangência). Quando o benefício é geração de emprego, impacta a comunidade (maior abrangência). Na percepção dos respondentes, a geração de renda leva ao desenvolvimento comunitário, sendo esse o impacto mais percebido. Esse resultado leva à outra dimensão na discussão do impacto social: além dos três tipos de resultado - outputs, outcomes e impacto, o impacto também pode ser avaliado em razão de sua abrangência, podendo estar associada, ou não, a um tipo de resultado. 
Outra reflexão obtida a partir das análises retoma a questão da relação causa-efeito no impacto social (Khandker et al., 2010 citado por Barki et al. 2015). Um caso em que fica claro esse cenário é a da empresa que faz pesquisa sobre o público $C$, D e E para auxiliar gestores na tomada de decisão de negócios que beneficiem essa população. A utilização por outras empresas do produto ou serviço que essa iniciativa oferta é que pode gerar benefícios sociais. Outras cinco empresas apresentaram característica similar. Nesses casos, esses negócios poderiam ser apontados como benefícios sociais indiretos.

\section{CONSIDERAÇÕES FINAIS}

Acredita-se que o modelo de negócios para NIS, principal contribuição teórica desta pesquisa, avança nos estudos da área revisitando e resgatando a teoria já existente e construindo uma ponte entre modelos conceituais até então tratados de forma independente. Dessa ponte emerge uma proposta de modelo de negócios detalhando os elementos dos NIS. 0 modelo apresenta os elementos que devem ser considerados na compreensão dos negócios com impacto social e como eles estão relacionados, em que as dimensões (1) rede de parceiros, (2) competências e (3) proposição de valor formam a base dos principais elementos que constituem a estrutura e operação de uma organização, a qual gera as receitas e os custos que compõem a (4) equação de lucro econômico e, como pano de fundo, a dimensão (5) equação de lucro social, que é a essência de um modelo de negócio com impacto.

Como contribuição para a prática, o modelo pode ser utilizado para melhor compreensão desse tipo de modelo de negócios. Alguns resultados do campo desta pesquisa já ilustram tal possibilidade. Mesmo os negócios inclusivos $(71 \%$ deles), tendo como princípio estimular a inserção da população de baixa renda, utilizam-se de mão de obra especializada. Apesar de aparentemente contraditório, o cenário é facilmente compreendido, uma vez que a grande maioria das iniciativas mapeadas é relacionada às áreas de saúde e educação, que exigem conhecimentos específicos. Para o bom atendimento da saúde, é imprescindível haver bons médicos, dentistas e enfermeiros, assim como docentes na educação. Por um lado, esse cenário traduz o alto índice de fornecedores com necessidades e qualificações especializadas, diminuindo a inserção da população de baixa renda como um output. Por outro, em um resultado de longo prazo, pode-se pensar em alternativas que busquem a capacitação dessa população, elevando seu nível educacional, o que configura o impacto social gerado.

Assim como a avaliação do impacto social, o processo de inovação social é um tema que tem recebido maior importância em razão de seu papel central nesse tipo de negócio (Barki et al., 2015). Um empreendedor concebeu seu negócio a partir de problemas que ele constatou no exercício da profissão: Sem dinheiro para comprar medicamentos, muitos pacientes paravam o tratamento. Após mapear medicamentos, vacinas e exames oferecidos gratuitamente pelo SUS, ele lançou uma ferramenta na internet que permite ao usuário encontrar o que procura rapidamente, auxiliando na continuidade do tratamento. O setor de habitação também pode desenvolver iniciativas inovadoras. Em uma das entrevistas, o entrevistado relatou que, após muitos estudos e reuniões, que envolveram também a comunidade, muitas famílias começaram a fazer pequenas obras e compravam materiais conforme tinham dinheiro. Essas reformas duravam muito tempo e acabavam por ficar muito caras. A solução encontrada pela empresa foi criar "kits de reforma", que custam entre $R \$ 1,5$ mil e $R \$ 4$ mil reais. No pacote estava incluído a reforma completa, desde a elaboração do projeto, a equipe de mão de obra e a compra do material. E isso tudo pode ser pago em forma de financiamento em até 12 vezes. Enfim, percebe-se que o processo de inovação social nos produtos e serviços ofertados emerge do conhecimento da realidade social mais do que de investimentos em pesquisa e desenvolvimento.

Ainda podem ser destacadas duas contribuições adicionais deste artigo. A primeira delas na proposta de definição de NIS como organizações que visam solucionar demandas relacionadas a problemas sociais, seja ofertando produtos e serviços, seja incluindo indivíduos ou grupos. Essas organizações devem promover sua própria sustentabilidade financeira, sendo facultativa a distribuição de lucros. A segunda, uma taxonomia contemplando três categorias: (1) produtos e serviços, (2) clientes e (3) estrutura de lucros.

Quando o objetivo de um artigo é apresentar uma nova posição conceitual, proposições pesquisáveis devem ser consideradas (Whetten, 2003). Existem relações, causais ou não, entre o tipo de benefício social e quem é impactado? É possível potencializar um tipo específico de benefício social ao focar em um grupo de impactados? As diferentes formas de distribuição de lucro influenciam o benefício social gerado? Essas são algumas proposições possíveis.

Outro caminho para futuras pesquisas: aplicar o modelo proposto junto aos diferentes atores do ecossistema, permitindo uma possível complementação dele.

Por fim, a maior compreensão dos benefícios e impactados pode auxiliar no desenvolvimento de métricas efetivas de avaliação dos resultados de negócios com impacto social, seja como outputs, outcomes ou impactos. Enquanto a avaliação de impacto social for um tópico de pesquisa tanto na visão retrospectiva quanto na visão prospectiva (Barki et al., 2015), o 
que evidencia ser um campo em aberto, as questões ambientais parecem mais bem endereçadas. 0 principal exemplo disso é o Protocolo de Kyoto, em que a comunidade científica coletou e definiu métricas e metas com relação às emissões de gases de efeito estufa. De acordo com Ribeiro, Ferreira, e Araújo (2011), não existe nada similar relacionado ao pilar da sustentabilidade social.

\section{REFERÊNCIAS}

Anderson, J., \& Billou, N. (2007). Serving the world's poor: Innovation at the base of the economic pyramid. Journal of Business Strategy, 28(2), 14-21. doi:10.1108/02756660710732611

Artemisia. (2014). Busca \& seleção de negócios: Setores foco - Saúde. Recuperado de www.artemisia.org.br/conteudo/frentes/busca/areas-atuacao/saude.aspx

Austin, J., Stevenson, H., \& Wei-Skillern, J. (2012). Social and commercial entrepreneurship: Same, different, or both? RAUSP-Revista de Administração da Universidade de São Paulo, 47(3), 370-384. doi:10.5700/rausp1055

Barki, E. (2014). Negócios com impacto social. RAE-Revista de Administração de Empresas, 54(5), 594. doi:10.1590/So034-759020140513

Barki, E. (2015). Negócios de Impacto: Tendência ou Modismo? GV-Executivo, 14(1). Recuperado de http://rae.fgv.br/gv-executivo

Barki, E., Comini, G., Cunliffe, A., Hart, S. L., \& Rai, S. (2015). Social entrepreneurship and social business: Retrospective and prospective research. RAE-Revista de Administração de Empresas, 55(4), 380-384. doi:10.1590/So034-759020150402

Boechat, C., Rosa, B., Oliveira, C. (2010). Levantamento do estágio dos negócios e mercados inclusivos em empresas no Brasil. Recuperado de www.fdc.org.br/pt/Paginas/default.aspx

Bonel, V., \& Veglio, F. (2011). Inclusive business for sustainable livelihoods. Field Actions Science Reports (on-line), 5. Recuperado de http://factsreports.revues.org/index.html

Burkett, I. (2013). Using the business model canvas for social enterprise design. Recuperado de http://knode.com.au/wp-content/uploads/ Knode_BusModCanv4SocEntDesign_E1LR_3op.pdf

Business Model Generation. (2013). The Business Model Canvas. Recuperado de www.businessmodelgeneration.com/canvas

Chesbrough, H., \& Rosenbloom, R. (2002). The role of the business model in capturing value from innovation: Evidence from Xerox corporation's technology spin-off companies. Industrial and Corporate Change, 11(3), 529-555. doi:10.1093/icc/11.3.529

Chu, M. (2007). Commercial returns at the base of the pyramid. Innovations, 2(1-2) , 115-146. doi:10.1162/itgg.2007.2.1-2.115

Comini, G. (2011). Mapas de soluções inovadoras: tendências de empreendedores na construção de negócios sociais e inclusivos. Recuperado de http://portal.institutowalmart.org.br/arquivos/m/map/ mapadeestudos/252_MapaEstudo1Finalpdf.pdf

Comini, G., Barki, E., \& Aguiar, L. T. (2012). A three-pronged approach to social business: A Brazilian multi-case analysis. RAUSP-Revis ta de Administração da Universidade de São Paulo, 47(3), 385-397. doi:10.1590/Soo80-21072012000300004
Dubosson-Torbay, M., Osterwalder, A., \& Pigneur, Y. (2002). E-business model design, classification, and measurements. Thunderbird International Business Review, 44(1), 5-23. doi:10.1002/tie.1036

Ebrashi, R. (2013). Social entrepreneurship theory and sustainable social impact. Social Responsibility Journal, 9(2), 188-209. doi:10.1108/ srj-07-2011-0013

Boechat, C., Rosa, B., Oliveira, C. (2010). Levantamento do estágio dos negócios e mercados inclusivos em empresas no Brasil. Recuperado de www.fdc.org.br/pt/Paginas/default.aspx

Goodman, L. A. (1961). Snowball sampling. The Annals of Mathematical Statistics, 32(1), 148-170.

Iris. (2014). Getting Started with IRIS. New York: Giin. Recuperado de http://iris.thegiin.org

Khandker, S. R., Koolwal, G. B., \& Samad, H. A. (2010). Handbook on impact evaluation: Quantitative methods and practices. Washington: World Bank Publications.

Ko, S. (2012). Viability of social enterprises: The spillover effect. Social Enterprise Journal, 8(3), 251-263. 10.1108/17508611211280782

Lambert, S., \& Davidson, R. (2013). Applications of the business model in studies of enterprise success, innovation and classification: An analysis of empirical research from 1996 to 2010. European Management Journal, 31(6), 668-681. doi:10.1016/j.emj.2012.07.007

Letts, C. W., Ryan, W., \& Grossman, A. (1997). Virtuous capital: What foundations can learn from venture capitalists. Harvard business review. Recuperado de https://hbr.org/.

Magretta, J. (2002). Why business models matter. Harvard Business Review. Recuperado de https://hbr.org/

Mair, J., \& Martí, I. (2006). Social entrepreneurship research: A source of explanation, prediction, and delight. Journal of World Business, 41(1), 36-44. doi:10.1016/j.jwb.2005.09.002

Marquez, P., Reficco, E., \& Berger, G. (2009). Negocios inclusivos en América Latina. Harvard Business Review. Recuperado de https:// hbr.org/

Michelini, L., \& Fiorentino, D. (2012). New business models for creating shared value. Social Responsibility Journal, 8(4), 561-577. doi:10.1108/17471111211272129

Moura, A. M. (2011). Facilitadores e dificultadores na implementação de um negócio inclusivo em três países de diferentes continentes. Dissertação (Mestrado em Administração) - Programa de Pós-Graduação em Administração, Faculdade de Economia, Administração e Contabilidade, Universidade de São Paulo, São Paulo.

Osterwalder, A. (2004). The business model ontology: A proposition in a design science approach. 169 f. Tese (Doutorado) - University of Lausanne, Lausanne.

Osterwalder, A., Pigneur, Y., \& Tucci, C. (2005). Clarifying business models: Origins, present and future of the concept. Communications of the Association for Information Systems, 16. Recuperado de http:// aisel.aisnet.org/cais/vol16/iss1/1/

Osterwalder, A., \& Pigneur, Y. (2011). Social Canvas I. Recuperado de www.socialbusinessmodelcanvas.com

Osterwalder, A., \& Pigneur, Y. (2009). Business model generation. Recuperado de www.businessmodelgeneration.com/book

Prahalad, C. K. (2005). A riqueza na base da pirâmide: Como erradicar a pobreza com o lucro. Porto Alegre: Bookman. 
Prahalad, C. K., \& Hart, S. (2002). The fortune at the bottom of the pyramid. Strategy+Business, Nova York. Recuperado de http://www.strategy-business.com/

Rahman, M., \& Hussain, M. (2012). Social business, accountability, and performance reporting. Humanomics, 28(2), 118-132. doi:10.1108/08288661211228889

Ribeiro, F., Ferreira, P., \& Araújo, M. (2011). The inclusion of social aspects in power planning. Renewable and Sustainable Energy Reviews, 15(9), 4361-4369. doi:10.1016/j. rser.2011.07.114

Sardana, G. (2013). Social business and Grameen Danone foods limited. Society and Business Review, Bingley, 8(2), 119-133. doi:10.1108/sbr01-2013-0002

Stanford. (s.d). Social Canvas II. Recuperado de http://sehub.stanford. edu/sites/default/files/Social\%2oBusiness\%20Model\%20Canvas_1.pdf

Teece, D. (2010). Business models, business strategy and innovation. Long Range Planning, 43(2-3), 172-194. doi:10.1016/j. Irp.2009.07.003

Teodósio, A. S., \& Comini, G. (2012). Inclusive business and poverty: Prospects in the Brazilian context. RAUSP-Revista de Administração da Universidade de São Paulo, 47(3), 410-421. doi:10.1590/s008021072012000300006

Thompson, J., \& Macmillan, I. (2010). Business models: Creating new markets and societal wealth. Long Range Planning. 43(2-3), 291-307. doi:10.1016/j.lrp.2009.11.002

Tiscoski, G., Rosolen, T., \& Comini, G. (2013). Empreendedorismo social e negócios sociais: Um estudo bibliométrico da produção nacional e internacional. Artigo apresentado no XXXVII Encontro da ANPAD. Rio de Janeiro, RJ. Artigo recuperado de http://www.anpad.org.br/ad$\mathrm{min} / \mathrm{pdf} / 2013$ EnANPAD_APB1365.pdf.
United Nations Development Programme. (2008). Creating value for all: Strategies for doing business with the poor. New York: UNDP, 2008. Recuperado de www.undp.org/gimlaunch/docs/GIM\%20Report\%20 Final\%20August\%202008.pdf

Van Slyke, D. M., \& Newman, H. K. (2006). Venture philanthropy and social entrepreneurship in community redevelopment. Nonprofit Management \& Leadership, 16(3), 345-368. doi:10.1002/nml.111

Whetten, D. A. (2003). O que constitui uma contribuição teórica? RAE-Revista de Administração de Empresas, 43(3), 69-73.

Wilson, F., \& Post, J. E. (2013). Business models for people, planet (\& profits): Exploring the phenomena of social business, a market-based approach to social value creation. Small Business Economics, 40(3), 715-737. doi:10.1007/s11187-011-9401-0

World Business Council for Sustainable Development - Netherlands Development Organization. (2011). Inclusive business: Creating value in Latin America. Geneve: WBCSD.

World Economic Forum. (2009). The Next billions: Unleashing business potential in untapped markets. Geneva: WEF. Recuperado de www3. weforum.org/docs/WEF_FB_UntappedMarkets_Report_2009.pdf

Yunus, M. (2008). Um mundo sem pobreza: A empresa social e o futuro do capitalismo. São Paulo: Ática.

Yunus, M., Moingeon, B., \& Lehmann-Ortega, L. (2010). Building social business models: Lessons from the Grameen experience. Long Range Planning, 43(2-3), 308-325. doi:10.1016/j.Irp.2009.12.005

Yunus, M. (2010). Criando um negócio social: Como iniciativas economicamente viáveis podem solucionar os grandes problemas da sociedade. Rio de Janeiro: Elsevier.

Zott, C., Amit, R., \& Massa, L. (2011). The business model: Recent developments and future research. Journal of Management, New York, 37(4), 1019-1042. doi:10.1177/0149206311406265 